\title{
Peningkatan Pengetahuan KESGILUT pada Anak Berkebutuhan Khusus melalui Aplikasi Teledentistry
}

\author{
Valendriyani Ningrum*1 , Abu Bakar ${ }^{2}$ \\ 1Program Studi Profesi Kedokteran Gigi, Fakultas Kedokteran Gigi, Universitas Baiturrahmah \\ 2Program Studi Sarjana Kedokteran Gigi, Fakultas Kedokteran Gigi, Universitas Baiturrahmah \\ *e-mail:: valend888@gmail.com¹, abuba.mmed@gmail.com²
}

\begin{abstract}
The parents of special needs children (SNC) problem in West Sumatra is the poor oral health of SNC, due to a lack of oral and dental health maintenance knowledge. The teledentistry application "SpecialSmile" is the solution offered. The aim is to improve oral health knowledge remotely. The method is carried out by preparing educational content in scientific articles or audiovisuals form. Program evaluation was collected by filling out a questionnaire containing 10 questions about oral health knowledge, before and after using this application. Data analysis was done descriptively. The results obtained from 49 users, before using the application only 22.95\% of parents had good knowledge and after using the application there was an increase of $80.33 \%$ of parents who had good knowledge regarding oral health maintenance among SNC. This program concludes that remote education using the SpecialSmile application can increase the knowledge of ABK parents about maintaining SNC's oral health.
\end{abstract}

Keywords: Education, Oral Health, Teledentistry, SpecialSmile Apps, Special Needs Children

\begin{abstract}
Abstrak
Permasalahan yang dihadapi oleh mitra orang tua Anak berkebutuhan khusus (ABK) di Sumatera Barat adalah kondisi kesehatan gigi dan mulut (KESGILUT) ABK yang buruk, karena kurangnya pengetahuan tentang pemeliharaan KESGILUT. Aplikasi teledentistry "SpecialSmile" merupakan solusi yang ditawarkan. Tujuannya untuk meningkatkan pengetahuan mengenai pemeliharan kesehatan gigi dan mulut secara jarak jauh. Metode pelaksanaan edukasi dilakukan dengan melakukan persiapan konten edukasi berupa artikel atau audiovisual. Evaluasi program dilakukan melalui pengisian kuesioner yang berisi 10 pertanyaan pengetahuan kesehatan gigi dan mulut, pada waktu sebelum dan sesudah menggunakan aplikasi ini. Analisis data dilakukan secara deskriptif. Hasil yang diperoleh dari 49 pengguna, sebelum menggunakan aplikasi hanya 22.95\% orang tua yang berpengetahuan baik dan sesudah menggunakan aplikasi terjadi peningkatan sebesar $80.33 \%$ orang tua yang berpengetahuan baik terkait pemeliharaan kesehatan gigi dan mulut. Kesimpulan dari program ini adalah edukasi jarak jauh dengan menggunakan aplikasi SpecialSmile dapat meningkatkan pengetahuan orang tua ABK tentang pemeliharaan kesehatan rongga mulut $A B K$.
\end{abstract}

Kata kunci: Edukasi, Kesehatan Rongga Mulut, Teledentistry, SpecialSmile Apps, Anak Berkebutuhan Khusus

\section{PENDAHULUAN}

Berdasarkan data Dinas Pendidikan Sumatera Barat, jumlah anak berkebutuhan khusus (ABK) di Provinsi Sumatera Barat mencapai 6.133 orang. Rincian ABK, 124 anak tunanetra, 897 anak tunarungu, 3.437 anak tunagrahita, 195 anak tunadaksa, 128 anak tunalaras, 798 anak autisme, 159 anak ADHD, dan 395 anak kesulitan belajar (Ganto, 2020).

Permasalan Kesehatan umum dan gigi butuh perhatian banyak pihak, karena berdasarkan hasil penelitian Ningrum dkk, 2020 melaporkan bahwa Penyandang disabilitas intelektual memiliki risiko lebih tinggi mengalami masalah kesehatan mulut. Jumlah karies atau gigi berlubang yang tinggi dikaitkan dengan kebersihan rongga mulut yang buruk, dan perilaku menyikat gigi yang belum efektif. Temuan penelitian ini menyiratkan bahwa ada kesenjangan dalam pengetahuan dan keterampilan perawatan kesehatan mulut pada individu ataupun orang tua/pengasuh (Ningrum et al., 2020). 
Tim melakukan observasi kesehatan gigi pada ABK dan wawancara dengan beberapa orang tua ABK pada bulan Maret 2020. Hasil observasi dilapangan ditemukan beberapa permasalahan Kesehatan gigi dan mulut seperti gigi berlubang, plak, karang gigi, gingivitis, halitosis (bau mulut), bruxism dan drooling. Dari hasil wawancara terdapat beberapa keluhan yakni, mayoritas orang tua menyadari kurangnya pengetahuan tentang pemeliharaan kesehatan gigi dan mulut pada $\mathrm{ABK}$, keterampilan menyikat gigi pada anak $\mathrm{ABK}$ masih terbatas (baik orang tua atau $\mathrm{ABK}$ ) dan masih jarang orang tua yang membawa $\mathrm{ABK}$ untuk datang ke praktik Dokter gigi. Alasan utama orang tua belum rutin ke Dokter gigi diantaranya kurang kooperatif perilaku beberapa ABK dan biaya perawatan gigi yang tidak terjangkau. Beberapa kendala tersebut menimbulkan dampak semakin banyaknya permasalahan kesehatan gigi dan mulut pada $A B K$. Oleh karena itu, permasalahan ini perlu dicarikan solusinya.

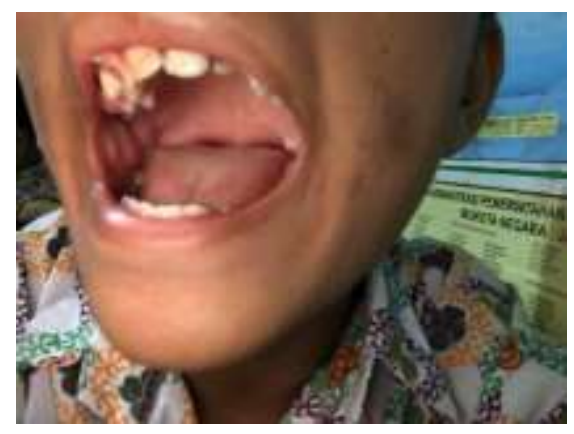

Gambar 1. Observasi tim dalam pemeriksaan rongga mulut ABK di Kota Padang (Dok. Lapangan, 12 Maret 2020)

Teledentistry merupakan salah satu solusi atas kondisi ini. Konsep ini merupakan perkembangan teknologi komunikasi dan informasi yang dapat meningkatkan efektivitas dan efisiensi, termasuk peningkatan akses ke layanan klinis, dan meningkatkan pengetahuan dan keterampilan. Teledentistry memberikan pilihan terbaik untuk skrining jarak jauh, diagnosis, konsultasi, perencanaan perawatan dan pendampingan di bidang kedokteran gigi. Dokter dan pasien akseptabilitasnya tinggi terhadap pendekatan ini (Irving et al., 2018). Studi lain melaporkan bahwa teledentistry terbukti efektif pada praktik kedokteran gigi anak, perawatan ortodontik, dan pengobatan penyakit mulut. Selain itu, penggunaan telekonsultasi dalam kedokteran gigi dapat menghemat biaya jika dibandingkan dengan konsultasi konvensional (Estai et al., 2018). Perkembangan teknologi ini merupakan solusi baru untuk melanjutkan praktik kedokteran gigi selama pandemi saat ini (Ghai., 2020).

Pengguna secara umum puas dengan model teledentistry melalui aplikasi android6. Pendekatan teledentistry seluler telah menunjukkan potensi untuk mendeteksi karies oklusal dari foto yang diambil dengan kamera ponsel cerdas. Penelitian ini menunjukkan bahwa teknologi telemedicine dan telepon seluler dapat digabungkan untuk menciptakan alat skrining yang murah dan andal (Estai et al., 2017). Studi di Arab Saudi membuktikan bahwa aplikasi teledentistry tidak hanya untuk konsultasi medis, akan tetapi secara signifikan juga meningkatkan pengetahuan ibu tentang kesehatan mulut anak (AlKlayb et al., 2020).

Tujuan dilaksanakan program pengabdian kepada masyarakat (PkM) adalah untuk meningkatkan pengetahuan mitra melalui konten artikel atau audiovisual edukasi kesehatan gigi dan mulut melalui penggunaan aplikasi android SpecialSmile.

\section{METODE}

Pelaksanaan dimulai dengan tahap inisiasi dengan melakukan analisis situasi dan kondisi mitra, setelah diketahui prioritas masalah dan solusi atas permasalahan mitra maka 
dilanjutkan pada tahap persiapan sebagai berikut: tahap pertama adalah perancangan desain aplikasi android dan website Special Smile (SS), tahap kedua melakukan penyusunan konten edukasi kesgilut pada ABK baik berupa artikel atau audiovisual, tahap ketiga dengan pembuatan website dan aplikasi android SS. Selanjutnya dilakukan sosialisasi, pelatihan, simulasi penggunaan aplikasi android dan website SS, monitoring serta perbaikan.

Konten edukasi ini akan disusun dan dipandu dengan modul dan trainer dari tim pelaksanaan secara sistematis dan komprehensif, agar orang tua memahami bagaimana cara menjaga kesgilut pada ABK. Konten edukasi yang dimaksud diantaranya Pengetahuan umum tentang anatomi rongga mulut, Jenis produk bahan makanan dan minuman yang berkaitan dengan kesgilut, Jenis-jenis sikat gigi adaptatif dan modifikasinya sesuai dengan kondisi $A B K$, Kandungan pasta gigi yang ideal bagi $A B K$, Hal-hal yang harus diperhatikan dalam menjaga kesgilut $A B K$, Permasalahan yang timbul pada rongga mulut sebagai dampak penggunaan obatobatan pada ABK, Kebiasaan-kebiasaan ABK yang berdampak buruk bagi kesgilut dan materimateri terkini lainnya terkait edukasi kesgilut untuk ABK.

Evaluasi PkM dilakukan dengan pengumpulan data melalui Google form untuk mengetahui tingkat pengetahuan orang tua terkait kesehatan rongga mulut ABK sebelum dan sesudah penggunaan aplikasi SpecialSmile dengan 10 pertanyaan yang sama. Indikator keberhasilan adalah 70\% pengguna aplikasi SpeciaSmile (Orang tua/Wali ABK) memeiliki pengetahuan yang baik terhadap cara menjaga kesgilut ABK.

\section{HASIL DAN PEMBAHASAN}

Program PkM ini dilaksanakan di wilayah Sumatera Barat melalui pendekatan yang digunakan adalah penyuluhan atau edukasi jarak jauh yang berfokus pada pengetahuan kesgilut ABK bagi orang tua/wali ABK melalui aplikasi android SpecialSmile yang dipandang mendukung pada kegiatan pemberdayaan masyarakat. Pelaksanaan kegiatan pengabdian dilakukan pada pertengahan bulan Juni s/d Juli 2021.

Kegiatan PkM telah mampu memberi perubahan bagi orang tua ABK di Sumatera Barat. Hal ini diketahui karena adanya peningkatan level pengetahuan kesehatan gigi dan mulut pada Orang Tua/Wali ABK yang diperoleh melalui konten edukasi artikel dan audiovisual pada aplikasi SpecialSmile(Gambar.2).

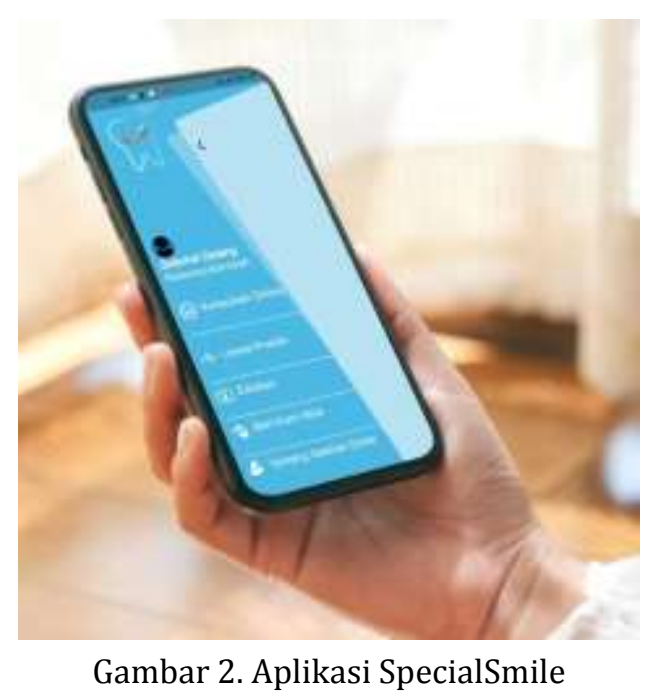

Sebelum mendapatkan pengetahuan melalui konten audiovisual, sebanyak 47 pengguna memiliki pengetahuan kurang (jawaban benar $<7$ dari 10 pertanyaan) dan berpengetahuan baik 
sebanyak 14 pengguna (jawaban benar $\geq$ dengan 7 dari 10 pertanyaan). Sesudah mendapatkan pengetahuan terjadi peningkatan pengetahuan baik sebanyak 49 pengguna (80.33\%) (Tabel 1).

Tabel 1. Distribusi frekuensi tingkat pengetahuan Orang tua/Wali ABK

\begin{tabular}{lcc}
\hline Kriteria Penilaian Pengetahuan & Frekuensi & Persentase \\
\hline Sebelum & & \\
Kurang & 47 & 77,05 \\
Baik & 14 & 22,95 \\
& & \\
Sesudah & & \\
Kurang & 12 & 19,67 \\
Baik & 49 & 80,33 \\
Total & $\mathbf{6 1}$ & $\mathbf{1 0 0}$ \\
\hline
\end{tabular}

Sebelum mendapatkan petunjuk cara menyikat gigi yang tepat, sebanyak 52 pengguna memiliki belum tepat cara menyikat gigi untuk anak ( $\leq 3$ dari 5 list skill dilakukan) dan 9 pengguna telah memiliki kemampuan menyikat gigi yang tepat ( $>3$ dari 5 list skill dilakukan). Sesudah mendapatkan petunjuk cara menyikat gigi yang tepat terjadi peningkatan kemampuan menyikat gigi yang tepat sebanyak 43 pengguna (70.49\%) (Tabel 2).

Tabel 2. Distribusi frekuensi cara menyikat gigi Orang tua/Wali ABK

\begin{tabular}{lll}
\hline Kriteria Penilaian cara menyikat gigi & Frekuensi & Persentase \\
\hline Sebelum & 52 & 85,25 \\
$\begin{array}{l}\text { Belum tepat } \\
\text { Tepat sesuai arahan Dokter Gigi }\end{array}$ & 9 & 14,75 \\
& & \\
Sesudah & 18 & \\
Belum tepat & 43 & 70,49 \\
Tepat sesuai arahan Dokter Gigi & $\mathbf{6 1}$ & $\mathbf{1 0 0}$ \\
Total & & \\
\hline
\end{tabular}

Kegiatan PkM ini sejalan dengan pernyataan bahwa pengembangan aplikasi dapat digunakan dapat menjadi solusi untuk menyelesaikan berbagai masalah pada mitra (Hermawati\& Armin, 2021). PkM edukasi ataupun penyuluhan jarak jauh telah banyak dikembangkan seperti media aplikasi penyuluhan berbasis android yang mampu mengakses informasi dan komunikasi secara efektif dan efisien dalam kegiatan penyuluhan pertanian, sehingga meningkatkan produktivitas (Pera \& Rendra, 2019). Hasil PkM ini menunjukkan hasil yang sama bahwa penyuluhan jarak jauh mampu meningkatkan pengetahuan mahasiswa tentang pencegahan keputihan (Yogho, 2020). Program PkM edukasi jarak jauh juga meningkatkan kepuasan mitra yang menyatakan bahwa penyuluhan jarak jauh menggunakan teknologi SMS Gateway menunjukkan hasil berupa 75\% responden memiliki kepuasan yang menganggap bahwa aplikasi tersebut dapat memberikan kontribusi yang sebagai upaya untuk meningkatkan keberdayaan mitra (Emerensiana, 2014).

\section{KESIMPULAN}

Program PkM yang telah dilaksanakan pada mitra orang tua/wali ABK sebagai upaya peningkatan akses edukasi kesehatan gigi dan mulut pada ABK di Sumatera Barat melalui aplikasi teledentistry, telah melampaui target PkM ini. Indikator keberhasilan PkM ini adalah $70 \%$ orang tua/wali $\mathrm{ABK}$ berpengetahuan baik terkait kesgilut ABK. Hasil program PkM ini sebanyak $80.33 \%$ orang tua/wali $\mathrm{ABK}$ memiliki pengetahuan yang baik terhadap cara menjaga 
kesehatan gigi dan mulut $\mathrm{ABK}$ dan $70.49 \%$ orang tua/wali $\mathrm{ABK}$ telah memiliki pengetahuan terkait cara menyikat gigi yang tepat. Dengan adanya program peningkatan edukasi kesehatan gigi dan mulut ABK melalui aplikasi SpecialSmile, diharapkan mampu meningkatkan kebersihan mulut $\mathrm{ABK}$ dan keberlanjutan untuk kualitas hidup ABK yang lebih baik.

\section{UCAPAN TERIMA KASIH}

Penulis mengucapkan terima kasih kepada Kemendikbud Ristek atas dukungan hibah PkM Nasional tahun 2020 terhadap pengabdian ini. Terima kasih juga kami sampaikan kepada Universitas Baiturahmah, UPTD. LDPI Kota Padang, dan FORKASI Sumatera Barat atas dukungan penuhnya sehingga PkM ini sukses dilaksanakan.

\section{DAFTAR PUSTAKA}

AlKlayb SA, Assery MK, AlQahtani A, AlAnazi M, Pani SC.(2017). Comparison of the Effectiveness of a Mobile Phone-based Education Program in Educating Mothers as Oral Health Providers in Two Regions of Saudi Arabia. J Int Soc Prev Community Dent, 7(3):110-115. doi: 10.4103/jispcd.JISPCD_95_17. Epub 2017 May 22. PMID: 28584780; PMCID:PMC5452563.

Emerensiana Ngaga.(2014). Pengembangan Aplikasi Penyuluhan Pertanian Tanaman Hortikultura Berbasis SMS Gateway. Jurnal Pekommas, Vol. 17 No. 1:33-42

Estai M, Kanagasingam Y, Xiao D, Vignarajan J, Bunt S, Kruger E, Tennant M.(2017). End-user acceptance of a cloud-based teledentistry system and Android phone app for remote screening for oral diseases. $J$ Telemed Telecare, 23(1):44-52. doi: 10.1177/1357633X15621847. PMID: 26721829.

Estai M, Kanagasingam Y, Tennant M, Bunt S (2018). A systematic review of the research evidence for the benefits of teledentistry. J Telemed Telecare, 24(3):147-156. doi: 10.1177/1357633X16689433. PMID: 28118778.

$\begin{array}{llll}\text { Ganto } \quad \text { Berita. } & \text { (2020). } & \text { Retrieved 2020 }\end{array}$ from https://www.ganto.co/berita/2654/mahyeldi-kota-padang-kota-pedulidisabilitas.html

Ghai S. (2020). Teledentistry during COVID-19 pandemic. Diabetes Metab Syndr, 14(5):933-935. doi: 10.1016/j.dsx.2020.06.029. PMID: 32593116; PMCID: PMC7297180.

Hermawati, F. A., \& Armin, A. P. (2021). Pemanfaatan Microsoft Excel untuk Aplikasi Data Pelanggan pada Pada Usaha Jasa Pembersihan Dan Perawatan Sepatu, Tas, Dan Topi. Dinamisia : Jurnal Pengabdian Kepada Masyarakat, 5(4). https://doi.org/10.31849/dinamisia.v5i4.6642

Irving M, Stewart R, Spallek H, Blinkhorn A.(2018). Using teledentistry in clinical practice as an enabler to improve access to clinical care: A qualitative systematic review. Journal of Telemedicine and Telecare, 24(3):129-146. doi:10.1177/1357633X16686776

Ningrum, V., Wang, W., Liao, H. et al.(2020). A Special Needs Dentistry Study of Institutionalized Individuals With Intellectual Disability in West Sumatra Indonesia. Sci Rep 10, 153. https://doi.org/10.1038/s41598-019-56865-2

Pera Nurfathiyah, Rendra Rendra.(2019). Penyuluhan Tentang Peremajaan Kelapa Sawit Dan Kelembagaan Petani Di Kecamatan Sungai Bahar Kabupaten Muaro Jambi . Jurnal Karya Abdi Masyarakat: Vol. 3 No. 1.

Yogho Prastyo.(2020). Efektifitas Penyuluhan Daring Pada Masa Pandemi Covid-19 Terhadap Tingkat Pengetahuan Remaja Perempuan Tentang Pencegahan Keputihan. Journal of Borneo Holistic Health, Volume 3 No. 2: 106-112. P ISSN 2621-9530 e ISSN 2621-9514 